\title{
ASSESSMENT AND MODELLING OF PARTICULATE MELON SHELL POLYESTER RESIN IMPREGNATE FOR COMPOSITE SPUR GEAR APPLICATION
}

\author{
OLABISI I. ADEYEMI ${ }^{1}$, EYERE EMAGBETERE ${ }^{2}$, ABRAHAM KEHINDE AWORINDE ${ }^{3}$, \\ FELIX ADEDAYO ISHOLA ${ }^{4} \&$ OLUWASEUN KILANKO \\ ${ }^{1,2}$ Research Scholar, Department of Mechanical Engineering, Federal University of Petroleum Resources,
} Effurun, Nigeria

3,4,5 Research Scholar, Department of Mechanical Engineering, Covenant University, Ota, Nigeria

\begin{abstract}
The use of polymer matrix gears is gaining popularity regarding adequate strength with weight reduction and better performance over the metallic gears, though the design requires extra thought and deviation from the norm. In this study, mechanical properties assessment of composite made of particulate Citrullus lanatus (melon) shell (PCLS) polyester resin impregnation for spur gear application is reported. The sample containing 5 wt\% of PCLS was analyzed for its tensile strength, modulus of elasticity, bulk modulus and shear modulus. The experimental results obtained gave a tensile strength, modulus of elasticity, bulk modulus and shear modulus of $85.08 \mathrm{MPa}, 2.59$ GPa, 2.54 GPa and 0.97 GPa, respectively. A torque of $140 \mathrm{~N}-\mathrm{m}$ was used to model the PCLS-based polymer spur gear in ANSYS environment. It was observed that PCLS reinforced polymer could be suitable for spur gear development under low loading conditions.

KEYWORDS: Citrullus lanatus shell, Melon, Mechanical properties, Modelling, Polyester resin \& Spur gear
\end{abstract}

Received: Nov 18, 2019; Accepted: Dec 09, 2019; Published: May 08, 2020; Paper Id.: IJMPERDJUN202043

\section{INTRODUCTION}

Polymer gears are proving to be the simplest and widely adopted means of power transmission over conventional (steel) gears due to some advantages, such as self-lubricating attributes, low cost, and good weight and noise reductions. However, modern machines are designed to operate at varying loads and speeds, and this leads to gear teeth failure at certain loads/speeds condition. Research attempts are ongoing to find alternative materials for gear manufacturing in a bid to overcome this drawback (Singh et al., 2018). Polyester matrix composite materials offer ample strength-to-weight ratio. In recent times, research on composites development is focused on the use of natural materials rather than synthetic. The shift from synthetic to natural fibre-based composites is due to the environmental friendliness and socio-economic benefits offered by natural materials (Raju et al., 2012; Razak et al., 2017; Sanjay et al., 2018). Agro-waste products are cheap and readily available for natural fibre-based composites. Their utilisation for various types of composites is increasingly investigated.

Agro-wastes have been proven suitable to impregnate polyester resin; they are cheap, readily available and possess desirable engineering properties (Abba et al., 2013). As reported in the literature, some agricultural by-products already used to produce polyester matrix composites includes, palm fronds (Ibrahim, 2015), palm kernel shell (Adeyemi et al., 2018), rice husk (Fernandesa et al., 2018; Kenechi et al., 2016; Zurina et al., 2004), Luffa (fibrous plant) (Daniel-Mkpume et al., 2019) wood (Kamdem et al., 2004; Karmarkar et al., 2007), corncob (Garadimani et al., 2015), groundnut shell (Panneerdhass et al., 2014; Usman et al., 2016), banana fibres - peels and stem (Devireddy \& Biswas, 2018; 
Pothan et al., 1997) and coconut shell (Bretotean et al., 2018). They are widely used for automobile applications (Noryani et al., 2018), gears (Rajeshkumar \& Manoharan, 2017) and other lightweight applications (Saravana Bavan \& Mohan Kumar, 2010).

Melon crop (Citrullus lanatus) has whitish seeds coated with brownish and lightweight shells. It is grown on a large scale for food in some African countries, but majorly in Nigeria (Ogbe \& George, 2012) and other West African countries (Obi et al., 2011). While the melon seed is nutritious, its shell (by-product) separated via mechanical shelling is useful for some purposes such as animal feeds, blending with fish feed to improve fish buoyancy (Obi et al., 2011). Also, it was reported to have nutritional value in the form of roughages in fowl feed (Ogbe \& George, 2012), and it is economically viable for metal matrix composites (Suleiman et al., 2018). Application of melon shells (MS) in composites development may involve carbonisation of the MS at controlled temperatures. When MS was used as a dopant in Al-12\%Si, the microstructural analysis of the composite showed a uniform oxide distribution, and the mechanical properties such as tensile strength, hardness, impact and wear resistance were improved significantly (Abdulwahab et al., 2017).

Polyester matrix composites can be applied in the production of lightweight gears (Adeyemi et al., 2018; Rajeshkumar \& Manoharan, 2017) following the established methodologies for gear design as reported in the literature (Anakhu et al., 2018; Bhandari, 2010; Gupta \& Chatterjee, 2018; Mahendran et al., 2015; Mao, 2007). Among gear types, spur gears are usually the first choice because of their design simplicity, excellent efficiency and broad applicability (Mahendran et al., 2015). Although polymer composite gears may become soft and wear out at a certain temperature (Khalil et al., 2011), their low cost, lightweight and reduced noise levels are favourable advantages. The melon crop is produced in large tonnage locally; its known application areas have been reported. However, there is a shortage of information regarding the application of its shell for polyester matrix composites development. This study intends to examine the use of MS as reinforcement for Polyester Resin for spur gears and to study what advantage(s) the use of such composites might have over the conventional spur gears made from cast steels.

\section{MATERIALS AND METHODS}

The materials employed in this study include particulate Citrullus lanatus (melon) shells, polyester resin, methyl ethyl ketone peroxide, cobalt naphthenate, A - Z grease, sodium hydroxide, deionized water and PVC mould cavity (Figure 1a).

\subsection{Methods}

The as-received Citrullus lanatus Shells (CLS) were washed and sun dried to remove impurities (Figure 1b). Afterwards, they were milled into granular form, treated with aqueous sodium hydroxide to expose the fibre surface for enhancing the mechanical strength, and the treated granular CLS was sundried and sieved (Figure 1c) using an $850 \mu \mathrm{m}$ sieve aperture.

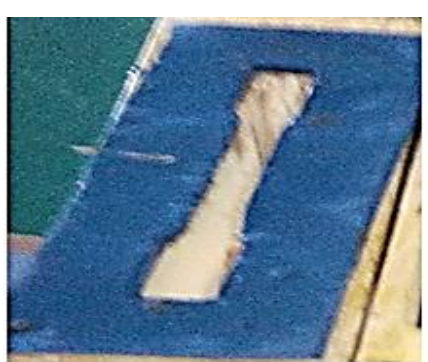

(a)



(b)

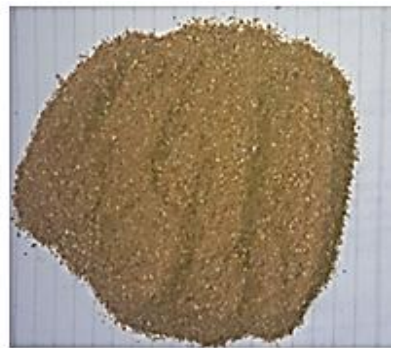

(c)

Figure 1: (a) PVC Mould (b) Citrullus lanatus (melon) Shells (c) Pulverised and Treated CLS 
Table 1 presents the \% wt composition of each component in the composite formulation

\begin{tabular}{|c|c|}
\hline Material & \% Weight composition \\
\hline Polyester resin and methyl ethyl ketone peroxide & 94.98 \\
\hline Cobalt naphthenate & 0.02 \\
\hline Pulverised Citrullus lanatus (melon) shells & 5.00 \\
\hline Total & 100 \\
\hline
\end{tabular}

\subsection{Characterisation}

The tensile test was conducted on the specimens (Figure 2) at the Material Testing Laboratories, Engineering Material Development Institute (EMDI) Akure, Nigeria, using an electronic universal testing machine (Model: INSTRON 3369).

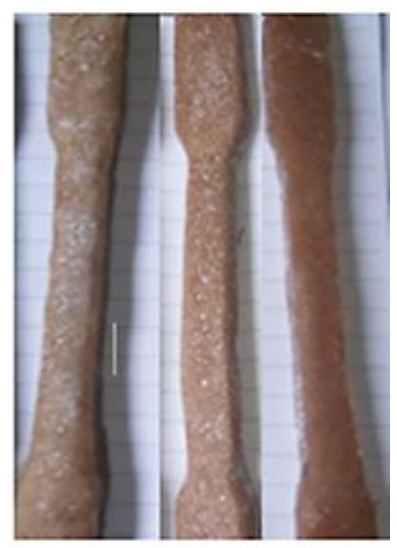

\subsection{Density Test}

Figure 2: PCLSRC Tensile Test Samples

The density of the specimens was determined using Archimedes' principle and calculated from Equation (1) (Khalil et al., 2011).

$$
\rho=\frac{W}{v_{1}-v_{2}}
$$

Where

$$
\begin{aligned}
& W=\text { weight of the sample in air }(g) \\
& v_{1}=\text { initial volume of water }\left(\mathrm{cm}^{3}\right) \\
& v_{2}=\text { final volume of water }\left(\mathrm{cm}^{3}\right)
\end{aligned}
$$

\subsection{Performance Modelling}

The particulate CLS reinforced polymer composite was modelled for gear application. The geometric model of a typical spur gear was drawn in AutoCAD and produced in Solid Works (Figure 3a and 3b, respectively) and the model was imported into ANSYS 15.0 environment for simulation (Figure 3 (c) \& (d)). 


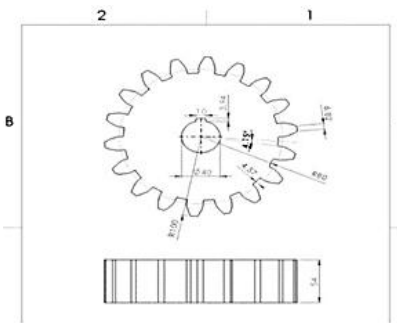

(a)



(b)

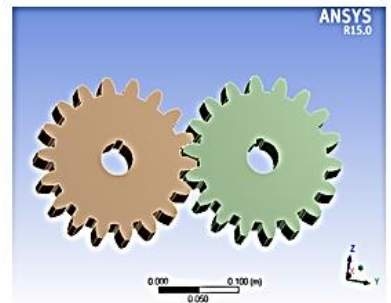

(c)

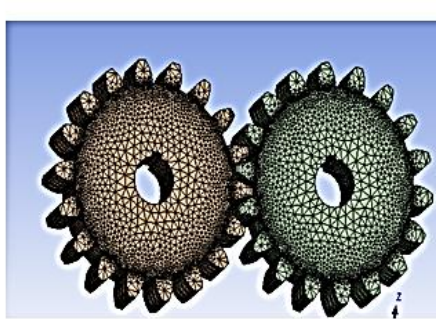

(d)

Figure 3: Spur Gear (a) Drawn in 2D (b) Modelled Using Solidworks (c) \& (d) Mesh Analysed in Ansys 15.0

\section{RESULTS AND DISCUSSION}

Physical Properties of the Pulverised Citrullus Lanatus Shells (PCLS)

Table 2 shows the physical properties of the PCLS.

Table 2 Physical Properties of PCLS

\begin{tabular}{ccccc}
\hline Materials & Particle size $(\boldsymbol{\mu m})$ & Texture & Colour & Density $\left(\mathbf{g} / \mathbf{c m}^{\mathbf{3}}\right)$ \\
\hline Pulverised Citrullus lanatus shells & 850 & Coarse & Light brown & 0.722 \\
\hline
\end{tabular}

\subsection{Mechanical Properties of the PCLS Reinforced Composite}

The average tensile strength $\left(\bar{\sigma}_{\mathrm{T}}\right)$, average load at break $(\overline{\mathrm{P}})$, average extension at break $(\overline{\mathrm{e}})$, ultimate tensile strength $($ UTS $)$ modulus of elasticity (E), bulk modulus (K) and shear modulus $(\mathrm{G})$ and Poisson's ratio (v) of the developed composite are presented in Table 3. The stress-strain plot of the composite under tensile loading is shown in Figure 4. It was observed that the failure occurred at $\bar{\sigma}_{\mathrm{T}}=85.08 \mathrm{MPa}$ with the corresponding average tensile strain $\left(\bar{\varepsilon}_{\mathrm{T}}\right)$ of $0.053 \mathrm{~mm} / \mathrm{mm}$.

Table 3: Tensile Test Features of the composite (PCLSRC)

\begin{tabular}{ccccccccc}
\hline$\overline{\mathbf{P}}(\mathbf{K N})$ & $\overline{\mathbf{e}}(\mathbf{m m})$ & $\overline{\boldsymbol{\sigma}}_{\mathbf{T}}(\mathbf{M P a})$ & $\overline{\boldsymbol{\varepsilon}}_{\mathbf{T}}(\mathbf{m m} / \mathbf{m m})$ & $\mathbf{U T S}(\mathbf{M P a})$ & $\mathbf{E}(\mathbf{G P a})$ & $\boldsymbol{v}$ & $\mathbf{K}(\mathbf{G P a})$ & $\mathbf{G}(\mathbf{G P a})$ \\
\hline 1.02 & 2.67 & 85.08 & 0.053 & 85.08 & 2.59 & 0.33 & 2.54 & 0.97 \\
\hline
\end{tabular}

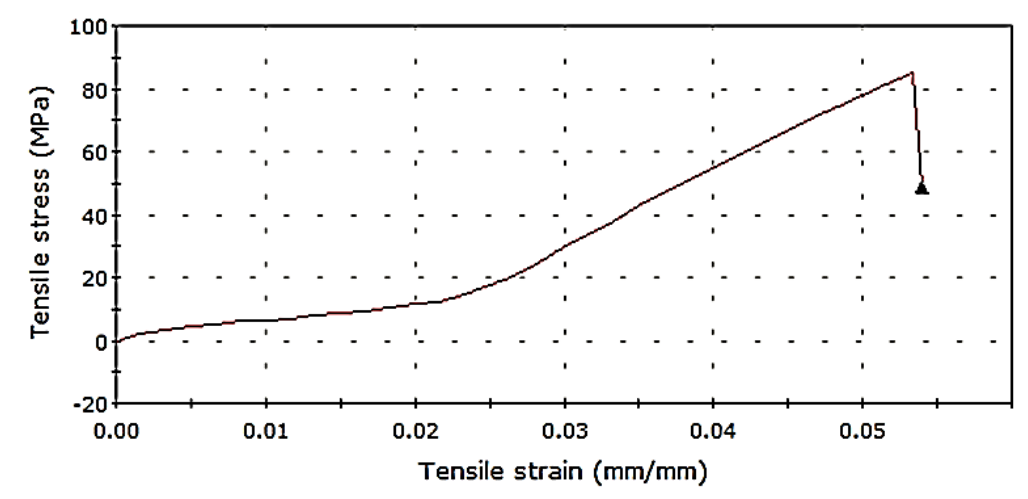

Figure 4: Stress-Strain Plot of the PCLSRC

The 85.08 MPa recorded as the tensile strength value for the PCLSRC is lower than that of cast steel (540 MPa) used to benchmark the spur gear design (Anakhu et al., 2018). However, the obtained tensile strength for the PCLSRC can be used to design and develop spur gears operating within the range of $\leqslant 85.08 \mathrm{MPa}$ loading condition. 


\subsection{Modelling of the PCLSRC Spur Gear}

With a torque of $140 \mathrm{~N}-\mathrm{m}$, the PCLSRC spur gear was modelled and the following stress characteristics namely; von-mises stress distribution, elastic strain, maximum deformation and shear stress were obtained as shown in Figure 5 (a), (b), (c) and (d) respectively.

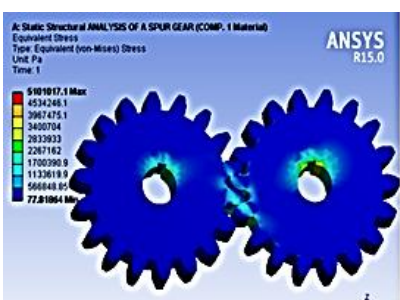

(a)

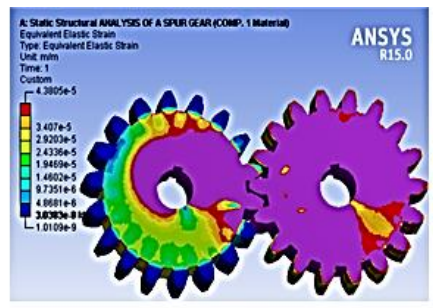

(b)



(c)



(d)

Figure 5: PCLSRC Spur Gear Analysis Result of (a) Von-Mises Stress Distribution (b) Elastic Strain (c) Maximum Deformation (d) Shear Stress

The Von-Mises stress is maximum around the key-way section of the gear (Figure 5a) due to stress concentration effect, the elastic strain is maximum in the region within the gear root circle, as shown in Figure 5b, deformation is maximum around the gear teeth (Figure 5c), while the shear stress is uniformly distributed, as shown with mono-colour in Figure 5d. The vonmisses stresses and maximum shear stress of the developed material compare favourably with that of the cast steel considered for the benchmark, as presented in Table 4, Figure 5c and 5d.

Table 4: Failure Analysis of the PCLSRC (5 wt. \% PCLS) Material Compared with Cast Steel

\begin{tabular}{lcc}
\multicolumn{1}{c}{ Parameters } & PCLSRC & Cast steel \\
\hline Max. Von-Mises stress (MPa) & 5.10 & 5.00 \\
Max. Elastic strain (mm/mm) & 0.04 & 0.04 \\
Max. Deformation (mm) & 0.11 & 0.04 \\
Max. Shear Stress (MPa) & 2.86 & 2.78 \\
\hline
\end{tabular}

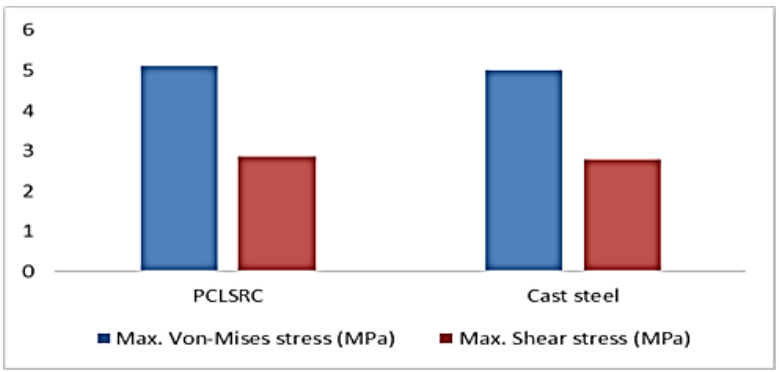

(a)

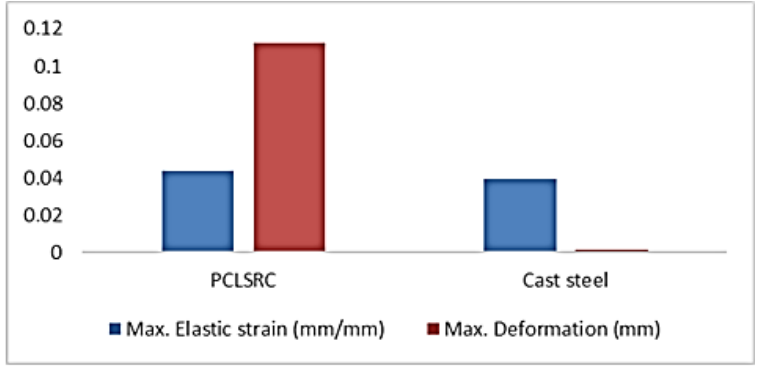

(b)

Figure 6: PCLSRC Spur Gear Plot of (a) Von-mises Stress and Shear Stress (b) Strain and Deformation

The maximum von-mises stress and shear stresses for both the developed material model and that of steel are shown in Figure 6a, while the maximum elastic strain and deformation are shown in Figure 6b. The obtained values compare favourably with those of the steel material. The maximum Von-misses stress of the modelled spur gear (5.101 MPa) is however lower than the value of yield stress (90.0 MPa) obtained during the uniaxial test of the PCLS based composite. Therefore, spur gears developed with the PCLS based composite are not likely to fail under the design conditions. 


\section{CONCLUSIONS}

The possibility of reinforcing polyester resin with melon shells powder (850-micron size) to form a composite material through an experimental and analytical approach was studied. The physical and mechanical properties of the developed natural fibre-based composite were determined for the investigation. The composite's static structural features were modelled and analysed for spur gear applications. The results showed that for a 5\% weight fraction of melon shell in the formulation, the material gave satisfactorily performances suitable for spur gear application where loading condition and torque requirement is less than $90.3 \mathrm{MPa}$ and $140 \mathrm{~N}$-m, respectively.

\section{ACKNOWLEDGEMENT}

The authors wish to acknowledge the financial support offered by Covenant University in the actualization of this research work for publication.

\section{REFERENCES}

1. Abba, H. A., Nur, I. Z., \& Salit, S. M. (2013). Review of Agro Waste Plastic Composites Production. Journal of Minerals and Materials Characterization and Engineering, 01(05), 271-279. https://doi.org/10.4236/jmmce.2013.15041

2. Abdulwahab, M., Dodo, R. M., Suleiman, I. Y., Gebi, A. I., \& Umar, I. (2017). Wear behavior of Al-7\%Si-0.3\%Mg/melon shell ash particulate composites. Heliyon, e00375. https://doi.org/10.1016/j.heliyon.2017

3. Adeyemi, O. I., Emagbetere, E., Oreko, U. B., Aworinde, A. K., Adeosun, O. S., Oyawale, A. F., ... Ajayi, O. O. (2018). Mechanical characterisation and modelling of a Pulverised Palm Kernel Spur Gear. Proceedings of the International Conference on Industrial Engineering and Operations Management, 2018, 2106-2114.

4. Anakhu, P. I., Abioye, A. A., Bolu, C. A., \& Azeta, J. (2018). Modeling of the kinematic geometry of spur gears using matlab. MATEC Web of Conferences, 153, 1-5. https://doi.org/10.1051/matecconf/201815303004

5. Bhandari, B. V. (2010). Design of Machine Element.

6. Bretotean, C. P., Craciun, A. L., Josan, A., \& Ardelean, E. (2018). Experimental study of sintered friction material with coconut fiber for brake pads. Materiale Plastice, 55(3), 389-392. Retrieved from http://www.revmaterialeplastice.ro

7. Balkees M. Al-Dabbagh \& Hanaa J. Al-Shimary, " Comparsion between Some Properties of Nano and Micro PVC Fibers Reinforced Polyester Composites ", International Journal of Metallurgical \& Materials Science and Engineering (IJMMSE), Vol. 6, Issue 2, pp. 33-38

8. Daniel-Mkpume, C. C., Ugochukwu, C., Okonkwo, E. G., Fayomi, O. S. I., \& Obiorah, S. M. (2019). Effect of Luffa cylindrica fiber and particulate on the mechanical properties of epoxy. International Journal of Advanced Manufacturing Technology, 102(9-12), 3439-3444. https://doi.org/10.1007//00170-019-03422-w

9. Devireddy, S. B. R., \& Biswas, S. (2018). Thermo-physical properties of short banana-jute fiber-reinforced epoxy-based hybrid composites. Proceedings of the Institution of Mechanical Engineers, Part L: Journal of Materials: Design and Applications, 232(11), 939-951. https://doi.org/10.1177/1464420716656883

10. Fernandesa, I. J., Santos, R. V., Dos Santos, E. C. A., Rocha, T. L. A. C., Junior, N. S. D., \& Moraes, C. A. M. (2018). Replacement of commercial silica by rice husk ash in epoxy composites: A comparative analysis. Materials Research, 21(3). https://doi.org/10.1590/1980-5373-MR-2016-0562 
11. Garadimani, K. R., Raju, G. U., \& Kodancha, K. G. (2015). Study on Mechanical Properties of Corn Cob Particle and E-Glass Fiber Reinforced Hybrid Polymer Composites. American Journal of Materials Science, 5(3C), 86-91. https://doi.org/10.5923/c.materials.201502.18

12. Gupta, K., \& Chatterjee, S. (2018). Analysis of Design and Material Selection of a Spur gear pairfor Solar Tracking Application. Materials Today: Proceedings, 5(1), 789-795. https://doi.org/10.1016/j.matpr.2017.11.148

13. Ibrahim, R. A. (2015). Tribological performance of polyester composites reinforced by agricultural wastes. Tribology International, 90, 463-466. https://doi.org/10.1016/j.triboint.2015.04.042

14. Kamdem, D. P., Jiang, H., Cui, W., Freed, J., \& Matuana, L. M. (2004). Properties of wood plastic composites made of recycled HDPE and wood flour from CCA-treated wood removed from service. Composites Part A: Applied Science and Manufacturing, 35(3), 347-355. https://doi.org/10.1016/j.compositesa.2003.09.013

15. Karmarkar, A., Chauhan, S. S., Modak, J. M., \& Chanda, M. (2007). Mechanical properties of wood-fiber reinforced polypropylene composites: Effect of a novel compatibilizer with isocyanate functional group. Composites Part A: Applied Science and Manufacturing, 38(2), 227-233. https://doi.org/10.1016/j.compositesa.2006.05.005

16. Kenechi, N.-O., Linus, C., \& Kayode, A. (2016). Utilization of Rice Husk as Reinforcement in Plastic Composites FabricationA Review. American Journal of Materials Synthesis and Processing, 1(3), 32-36. https://doi.org/10.11648/J.AJMSP.20160103.12

17. Khalil, H. P. S. A., Jawaid, M., \& Bakar, A. A. (2011). Woven hybrid composites: Water absorption and thickness swelling behaviours. BioResources, 6(2), 1043-1052. https://doi.org/10.15376/biores.6.2.1043-1052

18. Mohammed Ail Mutar \& Zainab Hamid Abdullah Attab, "Synthesis, Characterization, and Properties of New Unsaturated Polyesters Resins Reinforced with Some Fillers (Carbon Nano, Nano TiO2, TiO2 and ZnO) for Composite Application ", International Journal of Applied and Natural Sciences (IJANS), Vol. 6, Issue 3, pp. 79-100

19. Mahendran, S., Eazhil, K. M., \& Kumar, L. S. (2015). Design and Analysis of Composite Spur Gear. ARPN Journal of Engineering and Aplied $\quad$ Sciences, $10(11), \quad$ 42-53. Retrieved from http://www.arpnjournals.com/jeas/research_papers/rp_2015/jeas_0615_2208.pdf

20. Maо, K. (2007). A new approach for polymer composite gear design. Wear, 262(3-4), 432-441. https://doi.org/10.1016/j.wear.2006.06.005

21. Muhsin J. Jeewg, Abdal-Kareem F. Hassan \& Jawad. K. Zeboon, "Experimental and Numerical Investigation of the Dynamic Characteristic of Laminated Composite Plate Hybrid with Steel ", International Journal of General Engineering and Technology (IJGET), Vol. 3, Issue 1, pp. 27-36

22. Noryani, M., Sapuan, S. M., Mastura, M. T., Zuhri, M. Y. M., \& Zainudin, E. S. (2018). Material selection criteria for natural fibre composite in automotive component: A review. IOP Conference Series: Materials Science and Engineering, 368(1). https://doi.org/10.1088/1757-899X/368/1/012002

23. Obi, M. N., Kolo, R. J., \& Orire, A. M. (2011). The Production of Floating Fish Feed Using Melon Shell as a Floating Agent. International Journal of Science and Nature, 2(3), 477-482.

24. Ogbe, A. O., \& George, G. A. L. (2012). Nutritional and Anti-nutrient Composition of Melon Husks : Potential as Feed Ingredient in Poultry Diet. Research Journal of Chemical Sciences, 2(2), 35-39. Retrieved from www.isca.in

25. Panneerdhass, R., Gnanavelbabu, A., \& Rajkumar, K. (2014). Mechanical properties of luffa fiber and ground nut reinforced epoxy polymer hybrid composites. Procedia Engineering, 97, 2042-2051. https://doi.org/10.1016/j.proeng.2014.12.447 
26. Pothan, L. A., Thomas, S., \& Neelakantan, N. R. (1997). Short banana fiber reinforced polyester composites: Mechanical, failure and aging characteristics. Journal of Reinforced Plastics and Composites, 16(8), $744-765$. https://doi.org/10.1177/073168449701600806

27. Rajeshkumar, S., \& Manoharan, R. (2017). Design and analysis of composite spur gears using finite element method. IOP Conference Series: Materials Science and Engineering, 263(6). https://doi.org/10.1088/1757-899X/263/6/062048

28. Raju, G. U., Kumarappa, S., \& Gaitonde, V. N. (2012). Mechanical and physical characterization of agricultural waste reinforced polymer composites. Journal of Materials and Environmental Science, 3(5), 907-916.

29. Razak, M. F. A., Bakar, M. A. A., Kasolang, S., \& Ahmad, M. A. (2017). The effect of fiber treatment on abrasive wear properties of palm fiber reinforced epoxy composite. AIP Conference Proceedings, 1901. https://doi.org/10.1063/1.5010563

30. Sane Sreenivasulu \& K. Yogesh, "Compressive Properties of Polycarbonate Toughened Epoxy-Bamboo Fiber Composites ", IMPACT: International Journal of Research in Engineering \& Technology (IMPACT: IJRET), Vol. 2, Issue 10, pp. 13-16

31. Sanjay, M. R., Madhu, P., Jawaid, M., Senthamaraikannan, P., Senthil, S., \& Pradeep, S. (2018). Characterization and properties of natural fiber polymer composites: A comprehensive review. Journal of Cleaner Production, 172, 566-581. https://doi.org/10.1016/j.jclepro.2017.10.101

32. Saravana Bavan, D., \& Mohan Kumar, G. C. (2010). Potential use of natural fiber composite materials in India. Journal of Reinforced Plastics and Composites, 29(24), 3600-3613. https://doi.org/10.1177/0731684410381151

33. Singh, P. K., Siddhartha, \& Singh, A. K. (2018). An investigation on the thermal and wear behavior of polymer based spur gears. Tribology International, 118, 264-272. https://doi.org/10.1016/j.triboint.2017.10.007

34. Suleiman, I. Y., Salihu, S. A., \& Mohammed, T. A. (2018). Investigation of mechanical, microstructure, and wear behaviors of Al-12\%Si/reinforced with melon shell ash particulates. International Journal of Advanced Manufacturing Technology, 97(912), 4137-4144. https://doi.org/10.1007/s00170-018-2157-9

35. Usman, M. A., Momohjimoh, I., \& Gimba, A. S. B. (2016). Effect of Groundnut Shell Powder on the Mechanical Properties of Recycled Polyethylene and Its Biodegradability. Journal of Minerals and Materials Characterization and Engineering, 04(03), 228-240. https://doi.org/10.4236/jmmce.2016.43021

36. Zurina, M., Ismail, H., \& Bakar, A. A. (2004). Rice Husk Powder-Filled Polystyrene/Styrene Butadiene Rubber Blends. In J Appl Polym Sci (Vol. 92).

\section{AUTHORS PROFILE}



Olabisi I. Adeyemi specialises in sustainable materials and manufacturing with a specific research interest in bio-based PMCs development, assessment and analysis. He is a full-time academic staff of the Department of Mechanical Engineering, Federal University of Petroleum Resources, Effurun, Nigeria, and currently undertaking his Ph.D study at the University of Warwick, United Kingdom. 


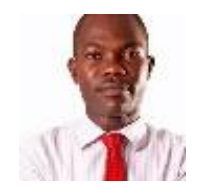

Eyere Emagbetere is currently a full-time lecturer in the Department of Mechanical Engineering, Federal University of Petroleum Resources, Effurun, Nigeria. He holds a Ph.D degree in mechanical engineering from the University of Ibadan. His research areas include numerical simulation, modelling and mechanics.

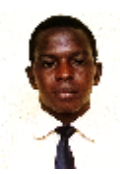

Abraham Kehinde Aworinde is a full-time lecturer and $\mathrm{PhD}$ student in the Department of Mechanical Engineering, Covenant University, Ota, Ogun State, Nigeria. His research interest is in the area of biodegradable polymer. He is currently working on the biomechanical properties of biodegradable reinforced polymer for orthopedic applications.



Felix A. Ishola is a full-time lecturer and Ph.D student in the Department of Mechanical Engineering, Covenant University, Ota, Ogun State, Nigeria. His research interests are Risk Analysis, Waste Management, Materials development, Design and Modelling. He is currently working on waste tyre to produce graphite for electrode production.

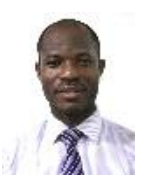

Oluwaseun Kilanko is a full-time lecturer in the Department of Mechanical Engineering, Covenant University. His main focus is in the area of design and simulation of mechanical systems. 